\title{
HISTOLOGICAL OBSERVATIONS ON GLYCOGEN RESERVES OF THE FOETUS AND NEWBORN INFANT
}

\author{
BY \\ JEAN M. SCOTT \\ From the Royal Maternity Hospital, Glasgow
}

(RECEIVED FOR PUBLICATION OCTOBER 15,1964 )

Every observer must be impressed by the ability of the foetal heart to continue beating under conditions of extreme oxygen lack. It has been known for many years that the foetus is specially endowed in this respect, but only recently has animal experimental work shown that survival may well be determined by the level of the foetal glycogen reserves, especially those of the myocardium (Shelley, 1961; Mott, 1961). Histological studies in this department over the past four years have shown that in stillbirths these levels vary considerably, but in newborn infants they are invariably low (Scott, 1961). Recently, however, our paediatric colleagues started to treat respiratory distress syndrome (RDS) of the newborn by means of intravenous alkalies and laevulose (Hutchison, Kerr, Douglas, Inall, and Crosbie, 1964). Striking differences in the glycogen reserves, even in babies coming to necropsy, were immediately noted, and these formed an interesting comparison with our earlier findings.

\section{Materials and Methods}

Post-mortem material was used. The bodies were refrigerated immediately after death and the majority of necropsies were carried out within 24 hours. Control cases were drawn from the original untreated series of 72 babies (Scott, 1961) and compared with 35 RDS babies, given bicarbonate and laevulose. Sections of liver and heart were examined as before for glycogen and fat, using a lead tetra-acetate Schiff method (LTAS) after picric alcohol fixation for the former and Sudan IV for the latter. The slides were graded on a,,++++++ basis, and the assessment made without reference to the clinical history or the therapy given.

\section{Results}

Though this paper is mainly concerned with the newborn infant, a few of the more important changes noted in stillbirths should be briefly mentioned here, as factors operative in intrauterine life undoubtedly influence the neonatal period, and some of these were not fully dealt with in the original paper. Nine stillbirths examined at that time showed variable amounts of glycogen in the myocardium. Seven, including two that were premature, had no stainable glycogen in their livers. The baby with the greatest amount of glycogen in its liver died from intracranial haemorrhage due to bilateral tentorial tears: death was sudden and unexpected and only a few cells in the periportal region of the liver lobule showed any sign of glycogen depletion; they failed to stain with LTAS, and in H. and E. sections glycogenic vacuolation was absent and the cytoplasm became shrunken and eosinophilic. Other similar cases have since been examined and it has been confirmed that in mature babies, where stress is of short duration, only the periportal region is affected, but, as foetal distress increases, depletion spreads throughout the whole lobule. Thus glycogen reserves may vary considerably in mature babies, but where the infant is premature the levels are invariably low.

Apart from cases of placental insufficiency, foetal blood loss, and Rhesus incompatibility, fatty change is uncommon in the myocardium of stillbirths (Scott, 1961), and this is also true of the liver. Only traces of fat were found in 2 of the 9 livers examined. One was a delayed labour with cord round the neck, the other an abruptio placentae and both were mature.

In the neonatal group, the 21 control cases and the 35 treated babies were compared and the amounts of glycogen found in the livers and hearts of both groups are shown in Table 1. In untreated control cases no stainable glycogen was found in the liver, but in those receiving laevulose, $57 \%$ had one plus or more. Cardiac glycogen stores were also enhanced. Only $33 \%$ of controls were positive and these merely one plus, but with treatment $76 \%$ became positive and $17 \%$ were actually ++ or more.

Fatty change in each group is shown in Table 2. At first the results seemed disappointing. More 
TABLE 1

GLYCOGEN CONTENT OF LIVER AND HEART IN BABIES TREATED WITH LAEVULOSE

\begin{tabular}{|c|c|c|c|c|c|c|}
\hline \multirow{2}{*}{ Organ } & \multirow{2}{*}{ Group } & \multirow{2}{*}{ No. } & \multicolumn{4}{|c|}{ Glycogen Grading ( $\%$ incidence) } \\
\hline & & & 0 & + & ++ & +++ \\
\hline \multirow[t]{2}{*}{ Liver } & Treated & 35 & $43(15)$ & $23(8)$ & $23(8)$ & $11(4)$ \\
\hline & Control & 21 & $100(21)$ & & & \\
\hline \multirow[t]{2}{*}{ Heart } & Treated & 29 & $24(7)$ & $59(17)$ & $14(4)$ & $3(1)$ \\
\hline & Control & 21 & $67(14)$ & $33(7)$ & & \\
\hline
\end{tabular}

Figures in brackets represent the number in each group.

TABLE 2

FATTY CHANGE IN LIVER AND HEART IN BABIES TREATED WITH LAEVULOSE

\begin{tabular}{|c|c|c|c|c|c|c|}
\hline \multirow{2}{*}{ Organ } & \multirow{2}{*}{ Group } & \multirow{2}{*}{ No. } & \multicolumn{4}{|c|}{ Fat Grading ( $\%$ incidence) } \\
\hline & & & 0 & + & ++ & +++ \\
\hline \multirow[t]{2}{*}{ Liver } & Treated & 32 & $10(3)$ & $31(10)$ & $40(13)$ & $19(6)$ \\
\hline & Control & 21 & $33 \cdot 3(7)$ & $33 \cdot 3(7)$ & $33 \cdot 3(7)$ & \\
\hline \multirow[t]{2}{*}{ Heart } & Treated & 25 & $56(14)$ & $4(1)$ & $36(9)$ & $4(1)$ \\
\hline & Control & 21 & $19(4)$ & $28 \cdot 5(6)$ & $28 \cdot 5(6)$ & $24(5)$ \\
\hline
\end{tabular}

Figures in brackets represent the number in each group.

fatty change was evident in the livers of treated cases. Only $10 \%$ were negative compared with $33 \%$ of controls, and $59 \%$ showed ++ or more. Less fatty change, however, was seen in the myocardium of the treated babies; $44 \%$ were positive compared with $81 \%$ of controls. This problem will be discussed later, but two important points should be mentioned here; first, the treated babies lived longer on the average (Fig. 1) and, secondly, $46 \%$ of them had terminal intraventricular haemorrhages.

Since administration of laevulose could obviously replenish glycogen stores, the next step was to see

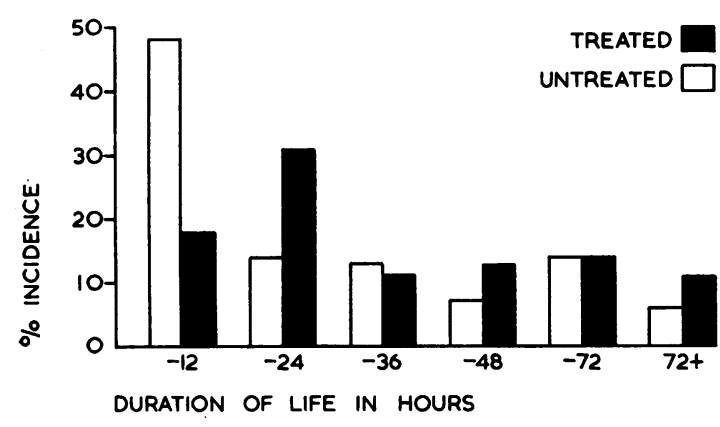

FIG. 1.--Duration of life in control and treated series. whether there was any relation between the amount given and the glycogen assessed histologically. The quantity of laevulose each baby received varied very much from case to case depending on the severity of the respiratory and metabolic acidosis and the necessity to give bicarbonate. As biochemical correction was achieved, however, maintenance therapy with $20 \%$ laevulose as well as bicarbonate could be given, the proportions depending on the Astrup readings (Hutchison et al., 1964). A total fluid intake of $60 \mathrm{ml} . / \mathrm{kg}$. in 24 hours was allowed. Thus it was possible, though highly unlikely, that all this could be given as laevulose, and for comparative purposes this amount of laevulose was taken as the ideal maximum on which all others were based, the values being expressed as percentages of it. The range was wide ( 7 to $85 \%$ ) but when the percentages were compared with the liver glycogen grading, it was found that if the very immature babies (less than 1,000 g.) and those mature babies over $2,500 \mathrm{~g}$. were excluded, some correlation was evident. The individual results of 27 babies whose weights fell into this range are shown in Fig. 2 and apart from one case, which has been ringed, it can be seen that as the percentage of laevulose rose, so the glycogen grading in the liver also increased. Considerable overlap is evident between the various groups, as one 


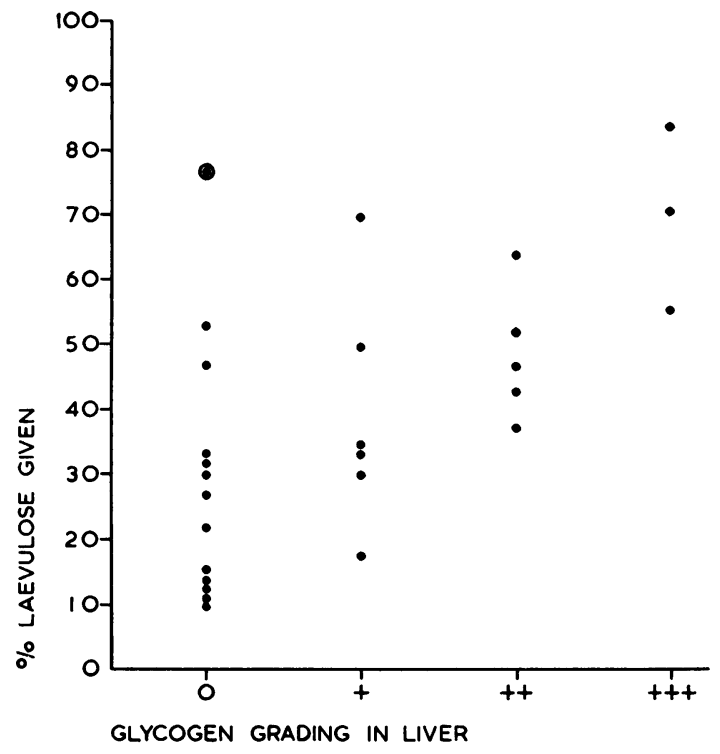

FIG. 2.-Glycogen grading in liver in relation to amount of laevulose given in 27 babies of $1 \cdot 0-2 \cdot 5 \mathrm{~kg}$.

might expect, where gradings based on a relatively crude histological assessment are used. The exception (ringed in Fig. 2) was a baby who, in spite of having $78 \%$ of the possible laevulose dose, had no stainable glycogen in its liver: it weighed only $1,030 \mathrm{~g}$. and like 3 other babies under 1,000 g. it seemed to be incapable of laying down glycogen adequately, even when laevulose was available. Only one baby under $1,000 \mathrm{~g}$. had any stainable glycogen in its liver and then only one plus, despite the fact that it had been given $83 \%$ of the possible laevulose dose. Three mature babies with weights over $2,500 \mathrm{~g}$. died of respiratory distress syndrome and were included in the treated series. The percentages of laevulose given were 22,24 , and 43 and the liver glycogen gradings +++ , + , and +++ , respectively. The numbers are small, but the lack of correlation is obvious.

Glycogen gradings in the myocardium were also analysed and related as before to the amount of laevulose administered during life, but for reasons that will be discussed later no correlation was found. It was also impossible to correlate glycogen storage with true blood glucose and fructose levels. In their clinical analysis Hutchison et al. (1964) showed that in 27 babies examined blood glucose levels were also raised after laevulose therapy but wide variations occurred. Of this group, 13 eventually came to necropsy, but the numbers were too small to form any opinion.
Deposition of glycogen itself within the various organs was interesting. Fig. 3 shows a liver with +++ glycogen grading. All the parenchymal cells contain glycogen, but in addition material giving a positive reaction is seen lying in portal veins. Presumably this represents carbohydrate that has been precipitated in processing. Livers with less glycogen tended to concentrate what they had round portal tracts (Fig. 4), but this was not always true. Sometimes glycogen could be seen round central veins as well as portal tracts, leaving the mid-zone free. On the other hand, it might be concentrated in one or other of these two sites in different lobules of the same liver (Fig. 5).

In the heart, heaviest concentrations were seen beneath the endocardium and round smaller vessels in the myocardium. Only rarely, with +++ grading, did the glycogen extend out to the pericardial surface.

\section{Discussion}

Histological assessment of glycogen from tissues obtained at necropsy has its limitations, but in the present circumstances the effects of therapy were so striking that grading was remarkably easy. This was partly due to the fact that most of the babies requiring treatment were premature and had RDS. Their initial glycogen reserves were therefore minimal. Certainly this was the case in the untreated control series (Scott, 1961), and similar findings have since been reported by Shelley (1964), using a more accurate chemical method.

This being so, the effects of therapy would naturally be more obvious, provided of course that the baby could utilize the laevulose presented to it. The findings show that the majority were capable of doing so. $57 \%$ had one plus or more glycogen in their livers, and this figure would probably have been higher had it been possible to give more laevulose in certain cases. Reference to Fig. 2 will show that 7 babies, or one-fifth of the series, had less than $25 \%$ of the possible laevulose dose.

In those given adequate amounts only the extremely premature babies around 1,000 g. seemed to be incapable of laying down glycogen. There were three such cases in the present series and it is possible that like very young unhatched chicks studied by Gill (1938) and early foetal guinea-pigs (Nemeth, Insull, and Flexner, 1954), their enzyme systems were incomplete, especially those concerned with glycogen synthesis. Certainly if these extremely premature babies are excluded, the rest of the premature babies lay down glycogen in their livers in amounts roughly proportional to the quantity of laevulose administered. 


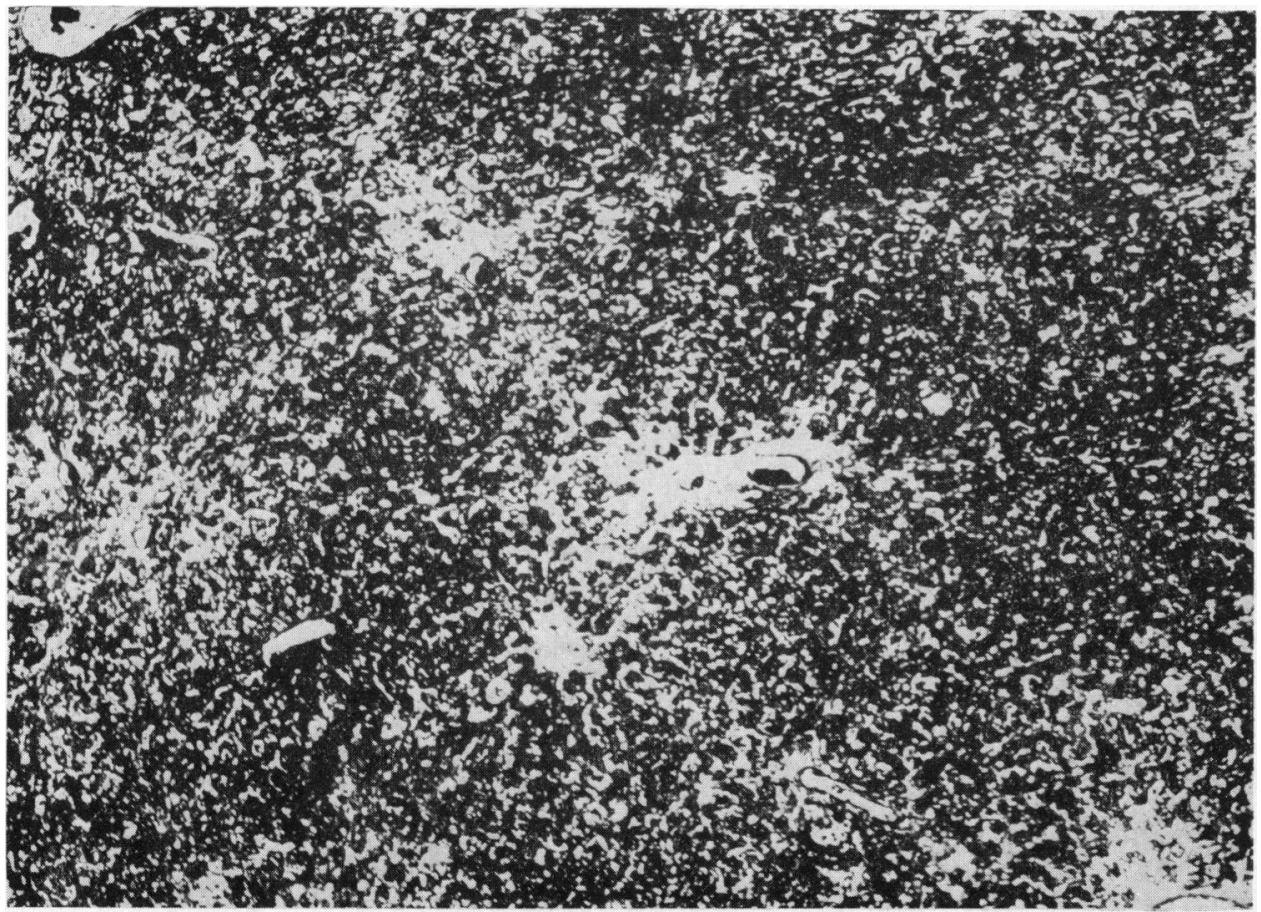

Fig. 3. - Liver, treated series, graded +++ for glycogen. Note positive material in portal tracts and central veins. (LTAS $\times$ 55.)

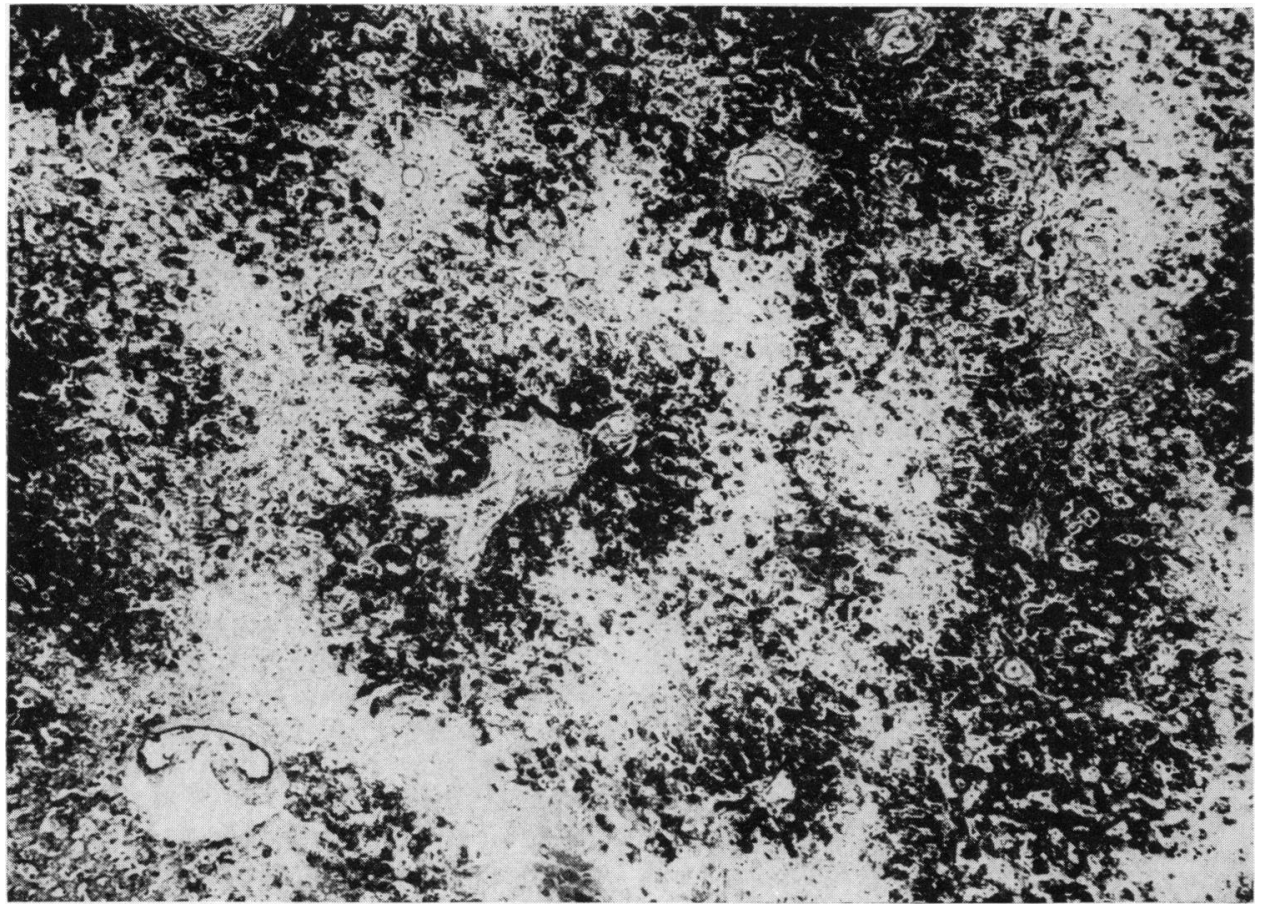

FIG. 4. - Liver, treated series, graded ++ for glycogen. Most of the material is round portal tracts less round central veins. (LTAS $\times$ 55.) 


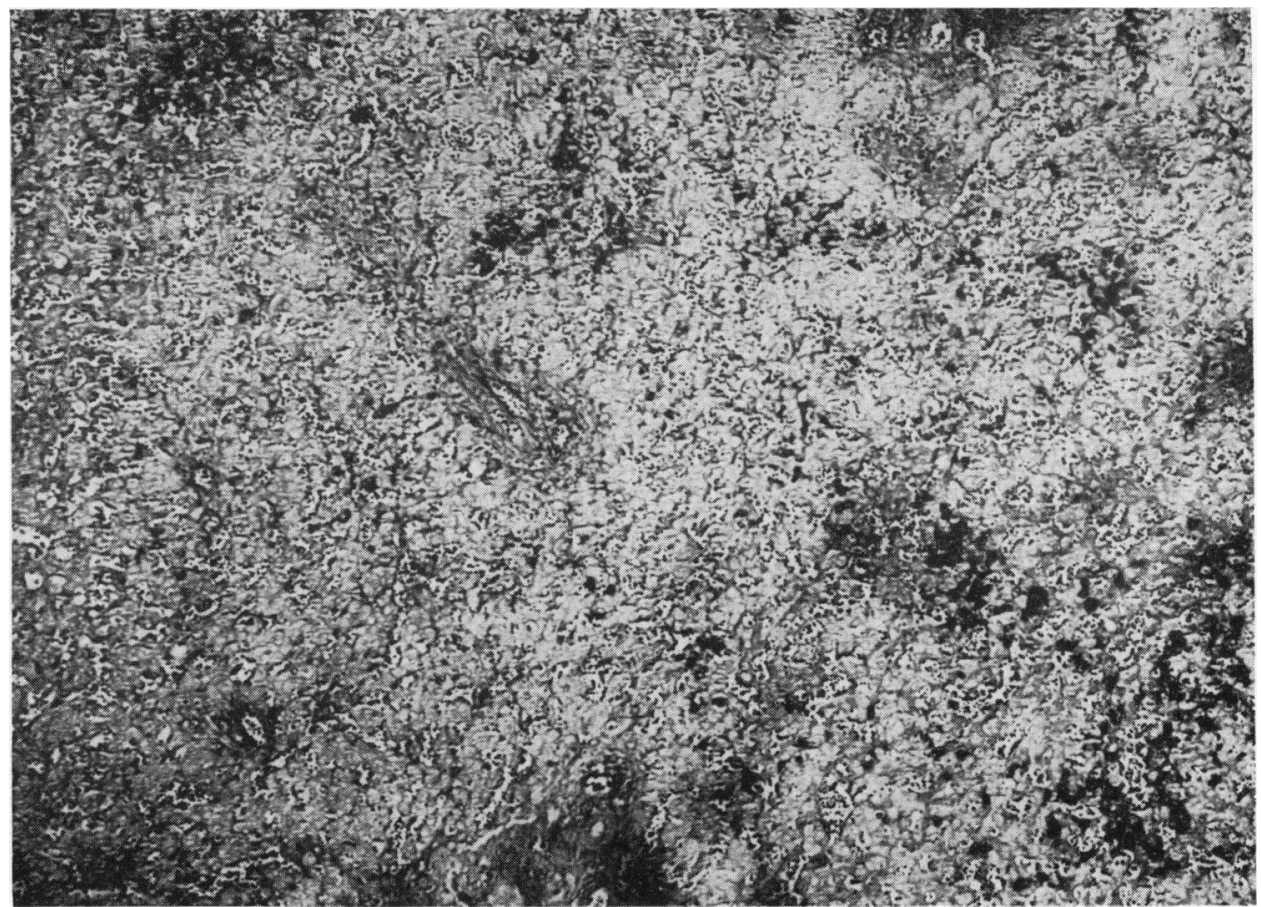

Fig. 5.-Liver, treated series, graded + for glycogen, which is irregularly distributed throughout the lobules. (LTAS $\times 55$.)

Whether the same is true of mature babies is by no means certain. The number of cases studied here is too small to come to any definite conclusion, but even with larger numbers, it is doubtful if the findings would be comparable. In mature babies there is such a wide range in liver glycogen at birth (Shelley, 1964, and personal observations) that any effect of therapy in the immediate neonatal period could easily be obscured.

Myocardial glycogen showed even less correlation with treatment given. Though twice as many positive cases were found in the treated group, there was no evidence of any quantitative relationship even in premature babies. However, the presence of intraventricular haemorrhage here $(46 \%)$ may well have altered the picture, for it has been shown that glycogen depletion is usually less marked, when this complication arises (Scott, 1961).

Fatty change in the myocardium was also less frequent in the treated group, only $44 \%$ compared with $81 \%$ in controls, but again this cannot be wholly attributed to treatment since intraventricular haemorrhage might also influence the picture (Scott, 1961).

Treatment certainly seemed to have no influence on fatty change in the liver. $90 \%$ of treated babies being positive for this compared with only $33 \%$ of controls. This was a disappointment, for it had been hoped that increase of hepatic glycogen would reduce fatty change. However, one has to remember that in a survey such as this only those babies coming to necropsy are seen, and the picture may be entirely different in survivors. Moreover the treated babies lived considerably longer than their control opposite numbers, $50 \%$ of whom died within 12 hours. One would, therefore, not expect to see much fatty change in the latter group. Indeed it only begins to appear with long and continued distress.

Apart from quantitative assessment of the glycogen, its distribution in histological sections was also interesting. In the heart it was found at 'points of entry' beneath the endocardium and around small vessels in the myocardium. In the liver, appearances were sometimes more difficult to explain. The administration of laevulose was often interrupted, when demands for bicarbonate increased, and the baby would then have to draw on its own glycogen reserves. If the depletion pattern followed that seen in stillbirths, then those cells around portal tracts would be the first to lose glycogen, followed later by cells in the mid-zone, until a stage would be reached when only small amounts might be found round central veins. Further administration of laevulose, at this point, would immediately replenish the stores 
of those cells nearest the periphery and possibly some in the mid-zone. Thus, if one takes into account the various stages in the above process, a ready explanation can be found for any of the irregular distribution patterns found in post-mortem material.

\section{Summary}

A histological assessment of glycogen storage and fatty change has been made on the livers and hearts of 35 babies treated with bicarbonate and laevulose via umbilical vein catheter for respiratory distress syndrome, and the findings have been compared with an earlier control series.

Apart from the very immature baby who seems to have reduced ability to lay down glycogen, storage increases roughly in proportion to the amount of laevulose administered. Myocardial glycogen also increases, though not proportionately as in the liver, and the reasons for this are discussed.

Fatty change was more common in the livers of treated babies but this could be due to the fact that they lived longer. On the other hand the myocardium showed less fatty change.

I should like to thank Dr. A. D. T. Govan for his advice and encouragement, and I am also grateful to Mr. David Johnston for technical assistance, to Mr. J. Sommerville for blood glucose estimations, and to Mr. Andrew Fraser and Mr. T. Pearston for photographic illustrations. Professor Hutchison very kindly gave me access to his clinical records.

\section{REFERENCES}

Gill, P. M. (1938). The effect of adrenaline on embryonic chick glycogen in vitro as compared with its effect in vivo. Biochem. J., 32, 1792.

Hutchison, J. H., Kerr, M. M., Douglas, T. A., Inall, J. A., and Crosbie, J. C. (1964). A therapeutic approach in 100 cases of the respiratory distress syndrome of the newborn infant. Pediatrics, 33, 956.

Mott, J. C. (1961). The ability of young mammals to withstand total oxygen lack. Brit. med. Bull., 17, 144.

Nemeth, A. M., Insull, W., Jr., and Flexner, L. B. (1954). Glycogenesis in the liver of the fetal guinea pig. J. biol. Chem., 208, 765.

Scott, J. M. (1961). Fatty change in the myocardium of the newborn. Brit. med. J., 2, 1746.

Shelley, H. J. (1961). Glycogen reserves and their changes at birth and in anoxia. Brit. med. Bull., 17, 137.

- (1964). Carbohydrate reserves in the newborn infant. Brit. med. J., 1, 273. 